\title{
Leishmania spp. Epidemiology of Canine Leishmaniasis in the Yucatan Peninsula
}

\author{
A. López-Céspedes, ${ }^{1}$ S. S. Longoni, ${ }^{1}$ C. H. Sauri-Arceo, ${ }^{2}$ M. Sánchez-Moreno, ${ }^{1}$ \\ R. I. Rodríguez-Vivas, ${ }^{2}$ F. J. Escobedo-Ortegón, ${ }^{3}$ M. A. Barrera-Pérez, ${ }^{3}$ M. E. \\ Bolio-González, ${ }^{2}$ and C. Marín ${ }^{1}$ \\ ${ }^{1}$ Departamento de Parasitología, Facultad de Ciencias, Universidad de Granada, Severo Ochoa s/n, 18071-Granada, Spain \\ ${ }^{2}$ Facultad de Medicina Veterinaria y Zootecnia, Campus de Ciencias Biológicas y Agropecuarias, Universidad Autónoma de Yucatán, \\ Km 15.5 Carretera Mérida-Xmatkuil, 4-116 Itzimná, Mérida, Yucatan, Mexico \\ ${ }^{3}$ Laboratorio de Zoonosis y VBD's, C.I.R. Dr. Hideyo Noguchi, Universidad Autónoma de Yucatán, \\ Avenida Itzaes No. $490 \times 59,97000$ Mérida, Yucatan, Mexico
}

Correspondence should be addressed to C. Marín, cmaris@ugr.es

Received 4 April 2012; Accepted 27 April 2012

Academic Editors: J. P. Akue, S. Angel, S. A. Babayan, M. Brunanska, and K. Y. Mumcuoglu

Copyright (C) 2012 A. López-Céspedes et al. This is an open access article distributed under the Creative Commons Attribution License, which permits unrestricted use, distribution, and reproduction in any medium, provided the original work is properly cited.

Canine Leishmaniasis is widespread in various Mexican states, where different species of Leishmania have been isolated from dogs. In the present study, we describe the detection of L. braziliensis, L. infantum, and L. mexicana in serum of dogs from the states of Yucatan and Quintana Roo in the Yucatan Peninsula (Mexico). A total of 412 sera were analyzed by ELISA using the total extract of the parasite and the iron superoxide dismutase excreted by different trypanosomatids as antigens. We found the prevalence of L. braziliensis to be $7.52 \%$, L. infantum to be $6.07 \%$, and L. mexicana to be $20.63 \%$, in the dog population studied. The results obtained with ELISA using iron superoxide dismutase as the antigen were confirmed by western blot analysis with its greater sensitivity, and the agreement between the two techniques was very high.

\section{Introduction}

Leishmaniasis is caused by a protozoan parasite called Leishmania, of which 21 species have been identified as pathogenic to humans. In most cases, it causes disease in animals and humans that become infected by accidentally entering endemic areas. It is a cosmopolitan disease of the most complex and diverse type, with significant overlap between different Leishmania species and their vectors, determining a complex ecology and epidemiology. It has three clinical forms: cutaneous, mucocutaneous, and visceral [1], with the visceral form being the most severe.

The disease is one of the less understood diseases of the world, affecting mainly developing countries. It is believed that about 350 million people are at risk of contracting the disease and more than 2 million new infections are recorded each year. Control programs of Leishmaniasis remain weak, showing a worrying increase in both mortality and morbidity in the world [2].

Dogs infected with this protozoan are the main reservoir of the disease and play a key role in its transmission to humans. Growing awareness that the control in humans depends on effective control of canine leishmaniasis has been promoted in recent years. Research on Leishmania infection in dogs has been conducted with hope of not only reducing the burden of disease in dogs, but also reducing the incidence of human leishmaniasis [3].

Canine Leishmaniasis is widespread in South America and is among the more important canine vector-borne diseases that occur in the region, mainly because of its great zoonotic relevance. Thus, many species of Leishmania have been isolated and molecularly characterized in dogs in South America, including L. amazonensis, L. braziliensis, L. colombiensis, L. infantum (syn. L. chagasi), L. mexicana, 


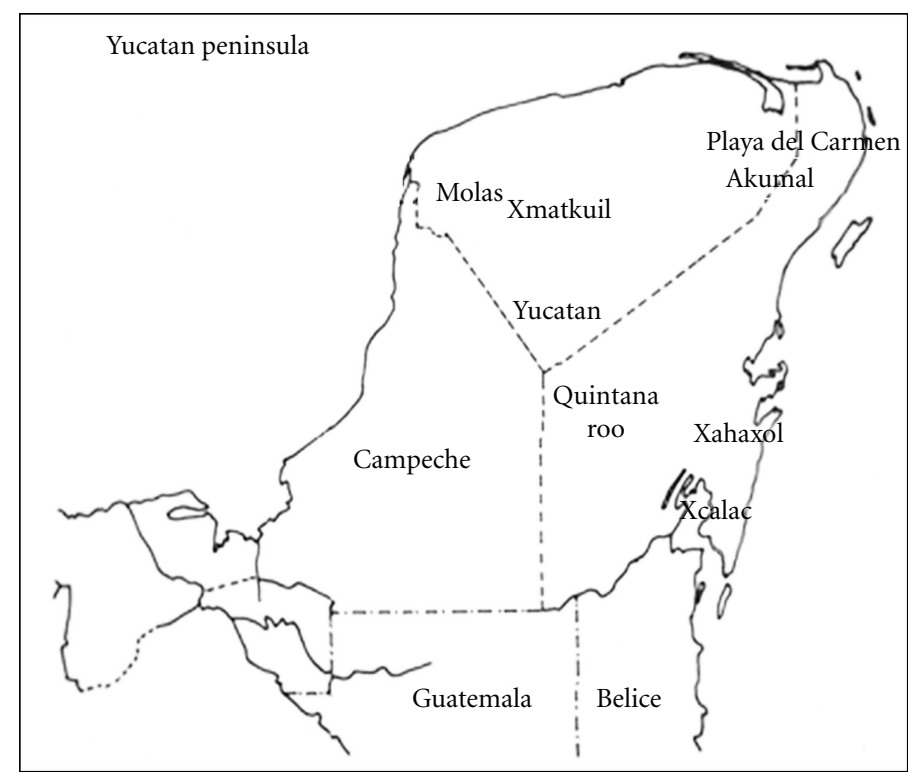

Figure 1: Map of the Yucatan Peninsula, Mexico, showing the geographical location of Molas and Xmatkuil in Yucatan State and Playa del Carmen, Akumal, Xcalac and Xahuachol in Quintana Roo State.

L. panamensis, L. peruviana, and L. pifanoi [4, 5]. L. infantum is the causative agent of canine visceral leishmaniasis, the most important form in South America, where dogs are its main reservoir [6]. L. braziliensis is the main causative agent of cutaneous leishmaniasis in dogs in this region [7].

The prevalence of Leishmania spp. in dogs in South America varies widely between regions. Depending on the diagnostic method used, the prevalence is usually from $25 \%$, to a maximum of $75 \%$ in endemic foci [8]. It is difficult to estimate the overall prevalence of Leishmania infection in dogs in South America due to the limited number of publications in some countries, the existence of methodological differences between studies (sample size or positivity criterion) and the limitations of serology (such as cross-reactions).

An important epidemiological feature is that dogs infected with $L$. infantum are apparently healthy, showing no clinical signs evident of the disease. In studies carried out in Brazil, $80 \%$ of seropositive dogs showed no symptoms of the disease. This information is critical because seropositive, but apparently healthy dogs, are a source of infection for flebotomos $[9,10]$.

Due to the variety of clinical signs of canine leishmaniasis, the diagnosis is very difficult. Several methods have therefore been developed to facilitate this task. However, it is essential to understand the basis of each test, its limitations and its clinical interpretation, and to consider the combination of more than one diagnostic test [11].

Many studies have been performed to discover a Leishmania-specific antigen that could increase the specificity of serodiagnosis [12-14]. One such candidate antigen is excreted iron-superoxide dismutase (Fe-SODe). This was found to be highly immunogenic and specific and is, therefore, a useful molecular marker for diagnosing infection with these parasites. The antigen was shown to provide good results in the diagnosis of visceral canine leishmaniasis [15] and of both cutaneous and mucocutaneous leishmaniasis in human serum in Peru [16]. It was also used in the diagnosis of visceral, cutaneous, and mucocutaneous leishmaniasis in dog serum in Mexico [17].

Here, we present the development of an ELISA using the antigen Fe-SODe excreted by L. mexicana, L. braziliensis, and $L$. infantum as a basis for the development of a serodiagnostic tool. Further, as a test of this method, we describe the percentage of stray dogs infected with these parasites at Molas, Xmatkuil, Playa del Carmen, Akumal, Xcalac and Xahuaxol on the Yucatan Peninsula (Mexico). We also demonstrate the lack of cross-reactions between the different Leishmania spp. and other trypanosomatids such as T. cruzi. The use of Fe-SODe could have significant diagnostic and epidemiological value for both canine leishmaniasis and other parasitic diseases caused by different species of the genus Leishmania.

\section{Materials and Methods}

2.1. Parasites and Culture. Promastigotes of L. braziliensis (MHOM/BR/75/M2904), L. infantum (MCAN/ES/2001/ UCM-10), L. mexicana (MHOM/BZ/82/Bel 21), were grown in axenic medium trypanosomes liquid (MTL; Gibco) supplemented with $10 \%$ heat-inactivated fetal bovine serum at $28^{\circ} \mathrm{C}$ in Falcon flasks.

2.2. Area of Study. The study was made in the towns of Molas and Xmatkuil in the state of Yucatan, and in the towns of Playa del Carmen, Akumal, Xcalac, and Xahaxol state of Quintana Roo (Figure 1). Both states have tropical 
and subtropical climates with warm and wet conditions, with annual average temperatures of $28^{\circ} \mathrm{C}$ (the maximum being $40^{\circ} \mathrm{C}$ ) and average humidity of $72 \%$, with annual rainfall of $1100 \mathrm{~mm}$.

2.3. Dog Populations and Collection of Samples. Of a total of 412 sera studied, 173 were collected in the state of Yucatan, with 147 in the region of the town Molas and 26 in Xmatkuil. The other 239 sera were collected in the state of Quintana Roo, with 63 in Playa del Carmen, 36 in Akumal, 127 in Xcalac, and 13 in Xahuaxol. For simplicity in presenting the results, the total of 412 sera was segregated into the following: sera 1-147 from Molas; 148-210 from Playa del Carmen; 211-246 from Akumal; 247-272 from Xmatkuil; 273-399 from Xcalac; 400-412 from Xahuaxol.

A sample of $5 \mathrm{~mL}$ of whole blood was drawn from the cephalic vein of each dog into assay tubes (Vacuttainer, Beckton-Dickinson, USA) and kept at $4^{\circ} \mathrm{C}$. The negative control sera (from 20 healthy or asymptomatic dogs) were taken from stray dogs put down by the veterinary services in Granada (Spain), which were not reactive to the Western-blot techniques.

2.4. Whole-Parasite Extract (Fraction $H$ ). The parasite culture (in the exponential growth phase) was concentrated by centrifugation at $1500 \mathrm{rpm}$ for $10 \mathrm{~min}$. The cell pellet was then washed twice with phosphate-buffered saline (PBS) and resuspended in ice-cold sodium Tris/ $\mathrm{HCl}$ ethylenediamine tetraacetic acid (EDTA) buffer $(0.25 \mathrm{M}$ sucrose, $25 \mathrm{mM}$ Tris/HCl, $1 \mathrm{mM}$ EDTA, $\mathrm{pH} 7.8$; buffer 1). The resulting pellet (0.5- $0.6 \mathrm{~g}$ wet weight $\mathrm{mL}^{-1}$ ) was suspended in $3 \mathrm{~mL}$ of buffer 1 and disrupted by three cycles of sonic disintegration (30 s each at $60 \mathrm{~V}$ ). The sonicated homogenate was centrifuged at $1500 \mathrm{rpm}$ for $10 \mathrm{~min}$ at $4^{\circ} \mathrm{C}$, and then the pellet was washed three times with buffer 1 for a total supernatant fraction of $9 \mathrm{~mL}$. This fraction was centrifuged $(2500 \mathrm{rpm}$ for $10 \mathrm{~min}$ at $4^{\circ} \mathrm{C}$ ) and the supernatant (fraction $\mathrm{H}$ ) was collected.

\subsection{Extraction and Partial Purification of the SOD Excreted} (Fe-SODe). Parasite forms in the exponential growth phase, obtained as described earlier, were concentrated by centrifugation at $1500 \mathrm{rpm}$ for $10 \mathrm{~min}$, the cell pellet was washed twice in serum free MTL medium, then the number of cells was counted in an hemocytometric chamber, and the cells were distributed into aliquots of $5 \times 10^{9}$ parasites $/ \mathrm{mL}$. Subsequently, the parasites were again grown in serumfree MTL medium for $24 \mathrm{~h}$, the supernatant was collected by centrifugation at $1500 \mathrm{rpm}$ for $10 \mathrm{~min}$ and then passed through a filter of $0.45-\mu \mathrm{m}$ pore size, and solid ammonium sulfate was added. The protein fraction, which precipitated at a salt concentration of between $35 \%$ and $85 \%$, was centrifuged ( $9000 \mathrm{rpm}$ for $20 \mathrm{~min}$ at $4^{\circ} \mathrm{C}$ ), redissolved in $2.5 \mathrm{~mL}$ of $20 \mathrm{mM}$ potassium phosphate buffer ( $\mathrm{pH}$ 7.8) containing $1 \mathrm{mM}$ EDTA (buffer 2), and dialyzed on a Sephadex G-25 column (Pharmacia, PD 10) previously balanced with buffer 2, to give a final volume of $2.5 \mathrm{~mL}$ (Fe-SODe fraction) [18].

The $\mathrm{H}$ and $\mathrm{Fe}-\mathrm{SODe}$ fractions were both used as antigen fractions in ELISA and Western blot assays. The protein content was determined using the Bradford reagent, based on the Bradford method (Sigma Immunochemical), with bovine serum albumin as standard [15].

2.6. Serological Assay: ELISA. Fractions $\mathrm{H}$ and Fe-SODe from the parasites (L. braziliensis, L. infantum, and L. mexicana), cultured and processed as described earlier, were used as the antigen fraction for the ELISA assay in all cases. The total homogenate (fraction $\mathrm{H}$ ) and semi-purified protein fraction (Fe-SODe), at a concentration of 5 and $1.5 \mu \mathrm{g}$, respectively, were coated onto polystyrene microtiter plates (Nunc) in carbonate buffer $(\mathrm{pH} 8.2)$ for $2 \mathrm{~h}$ at $37^{\circ} \mathrm{C}$. The antigen remaining on the plate was eliminated by washing three times with PBS-Tween 20 0.05\% (washing buffer). Free adsorption sites were blocked by incubation $(2 \mathrm{~h}$ at $37^{\circ} \mathrm{C}$ ) with blocking buffer (PBS-Tween $200.2 \%$, bovine serum albumin $1 \%$ ). The antibodies retained at a serum dilution of $1 / 100$ in PBS were developed with peroxidaselabeled sheep anti-total-dog immunoglobulin antibodies at a dilution of $1: 1000$ as conjugate. The enzyme reaction was developed in the dark with the chromogenic substrate ophenylenediamine dihydrochloride (Sigma, Madrid, Spain) and $10 \mu \mathrm{L}$ of $30 \% \mathrm{H}_{2} \mathrm{O}_{2}$ per $25 \mathrm{~mL}$ for $20 \mathrm{~min}$. The reaction was stopped by addition of $50 \mu \mathrm{L}$ of $3 \mathrm{~N} \mathrm{HCl}$, and the absorbance was read at $492 \mathrm{~nm}$ in a microplate reader (Metertech $\Sigma$ 960). All samples were analyzed in triplicate in polystyrene microtiter plates, and the mean and standard deviations of the optical densities of the negative control sera (10 healthy dogs) were used to calculate the cutoff value (mean +3 standard deviation).

2.7. Western Blot Analysis. The antigen fraction of Fe-SODe (at a concentration of $1.5 \mu \mathrm{g}$ protein) from $L$. braziliensis, $L$. mexicana., and L. infantum was run on Isoelectric focusing (IEF) 3-9 gels and then transferred to nitrocellulose, for $30 \mathrm{~min}$, as described in the Phast System manual. The membrane was blocked for $2 \mathrm{~h}$ at room temperature using $0.4 \%$ gelatin and $0.2 \%$ Tween 20 in PBS, then washed three times with $0.1 \%$ Tween 20 in PBS (PBS-T), and incubated for $2 \mathrm{~h}$ at room temperature with dog sera at a dilution of $1 / 100$. Before washing again, the membrane was further incubated for $2 \mathrm{~h}$ at room temperature with a second antibody, namely anti-dog immunoglobulin G (Fc-specific) peroxidase conjugate (Sigma Immunochemical; dilution 1/1000). After washing as described earlier, the substrate diaminobenzidine $(0.5 \mathrm{mg} / \mathrm{mL}$ in buffer Tris/HCl $0.1 \mathrm{M}$, pH 7.4, containing $\left.1 / 5000 \mathrm{H}_{2} \mathrm{O}_{2}[10 \mathrm{v} / \mathrm{v}]\right)$ was added and the reaction was stopped by washing several times with distilled water.

\section{Results}

The 412 sera of dogs from different regions of the Yucatan Peninsula (173 from the state of Yucatan and 239 from the state of Quintana Roo) were assayed by ELISA using the total extract of the parasite $(\mathrm{H})$ and the excreted iron-superoxide dismutase (Fe-SODe) of L. braziliensis, L. infantum and $L$. mexicana as the antigen. 
Table 1: Prevalence of antibodies to Leishmania braziliensis, L. infantum and L. mexicana infection in dogs from Peninsula of Yucatan (Mexico).

\begin{tabular}{|c|c|c|c|c|c|}
\hline \multicolumn{6}{|c|}{ Leishmania mexicana } \\
\hline \multicolumn{6}{|c|}{ Yucatan Peninsula 20.63\% } \\
\hline \multicolumn{3}{|c|}{ Yucatan State $26.59 \%$} & \multicolumn{3}{|c|}{ Quintana Roo State $16.32 \%$} \\
\hline $\begin{array}{l}\text { Molas } \\
30.61 \%\end{array}$ & $\begin{array}{c}\text { Xmatkuil } \\
3.85 \%\end{array}$ & $\begin{array}{c}\text { Playa del } \\
\text { Carmen } \\
23.81 \%\end{array}$ & $\begin{array}{c}\text { Akumal } \\
30.56 \%\end{array}$ & $\begin{array}{l}\text { Xcalak } \\
9.45 \%\end{array}$ & $\begin{array}{c}\text { Xahuaxol } \\
7.69 \%\end{array}$ \\
\hline \multicolumn{6}{|c|}{ Leishmania braziliensis } \\
\hline \multicolumn{6}{|c|}{ Yucatan Peninsula 7.52\% } \\
\hline \multicolumn{3}{|c|}{ Yucatan State $11.56 \%$} & \multicolumn{3}{|c|}{ Quintana Roo State $4.60 \%$} \\
\hline $\begin{array}{l}\text { Molas } \\
10.20 \%\end{array}$ & $\begin{array}{c}\text { Xmatkuil } \\
19.23 \%\end{array}$ & $\begin{array}{c}\text { Playa del } \\
\text { Carmen } \\
3.17 \%\end{array}$ & $\begin{array}{c}\text { Akumal } \\
8.33 \%\end{array}$ & $\begin{array}{l}\text { Xcalak } \\
4.72 \%\end{array}$ & $\begin{array}{c}\text { Xahuaxol } \\
0.00 \%\end{array}$ \\
\hline \multicolumn{6}{|c|}{ Leishmania infantum } \\
\hline \multicolumn{6}{|c|}{ Yucatan Peninsula 6.07\% } \\
\hline & atan State 1 & & & a Roo Sta & \\
\hline Molas $2.04 \%$ & $\begin{array}{c}\text { Xmatkuil } \\
0.00 \%\end{array}$ & $\begin{array}{c}\text { Playa del } \\
\text { Carmen } \\
3.17 \%\end{array}$ & $\begin{array}{c}\text { Akumal } \\
0.00 \%\end{array}$ & $\begin{array}{c}\text { Xcalak } \\
15.75 \%\end{array}$ & $\begin{array}{c}\text { Xahuaxol } \\
0.00 \%\end{array}$ \\
\hline
\end{tabular}

The results obtained with the ELISA using the total extract as antigen (ELISA/H) indicated the prevalence of L. braziliensis to be $2.18 \%$ in the peninsula. In the state of Yucatan, four positive sera were detected (prevalence = $2.31 \%$ ) of which three were from Xmatkuil (prevalence = $11.54 \%$ ) and one was from Molas (prevalence $=0.68 \%$ ). In the state of Quintana Roo, there were five positive sera (prevalence $=2.09 \%$ ), one from Playa del Carmen (prevalence $=1.59 \%)$, another from Akumal (prevalence $=$ $2.78 \%$ ), and three from Xcalac (prevalence $=2.36 \%$ ). As for the ELISA/Fe-SODe, the prevalence of L. braziliensis detected from total sera from dogs analyzed was $7.52 \%$, with $11.56 \%$ in the state of Yucatan and $4.60 \%$ in the state of Quintana Roo (Table 1). Fifteen sera were detected as positive from Molas (prevalence $=10.20 \%$ ), five were positive from Xmatkuil (prevalence $=19.23 \%$ ), two from Playa del Carmen (prevalence $=3.17 \%$ ), three from Akumal ( prevalence $=8.33 \%$ ), and six from Xcalac (prevalence $=$ $4.72 \%$ ) (Table 2 ). To verify these data, sera were analyzed by western blot analysis using Fe-SODe as the antigen (western blot analysis/Fe-SODe). This showed the prevalence of $L$. braziliensis to be $6.31 \%$ in the peninsula, $8.67 \%$ in the state of Yucatan, and $4.60 \%$ in Quintana Roo. The agreement between the ELISA/Fe-SODe and western blot analysis/FeSODe for L. braziliensis was $84 \%$.

The prevalence of $L$. infantum indicated by ELISA/H was $0.49 \%$, with only two positive sera; one serum from Molas (prevalence $=0.68 \%$ ) and one from Xcalac (prevalence $=$ $0.79 \%)$. However, the prevalence of total sera tested with ELISA/Fe-SODe was $6.07 \%$, with three positive sera from Molas (prevalence $=2.04 \%$ ), twenty positive sera from Xcalac (prevalence $=15.75 \%$ ), and two positive sera from Playa del Carmen (prevalence $=3.17 \%$, Table 3). Using western blot analysis/Fe-SODe of $L$. infantum, the total prevalence was 5.58\%, with $2.04 \%$ in Molas, $14.17 \%$ in Xcalac and $3.17 \%$ in Playa del Carmen. The agreement between the techniques (ELISA/Fe-SODe and western blot analysis/Fe-SODe) for L. infantum was $92 \%$.

The ELISA/H for L. mexicana resulted in 16 positive sera from the total (prevalence $=3.88 \%$ ). Eight positive sera were from the state of Yucatan with seven from Molas (prevalence $=4.78 \%$ ) and one from Xmatkuil (prevalence $=3.85 \%$ ). The other eight positive sera were from the state of Quintana Roo; two from Playa del Carmen (prevalence $=3.17 \%$ ), three from Akumal (prevalence $=8.33 \%$ ), two from Xcalac (prevalence $=1.57 \%$ ), and one from Xahaxol (prevalence $=7.69 \%$ ). However, the ELISA/Fe-SODe resulted in the detection of 85 positive sera from the total indicating a prevalence of $20.63 \%$ (Table 1). From these, 46 positive sera were from the state of Yucatan (prevalence $=26.59 \%$ ), with 45 positive from Molas (prevalence $=30.61 \%$ ) and one from Xmatkuil (prevalence $=3.85 \%$ ). Thirty-nine positive sera were from Quintana Roo (prevalence $=16.32 \%$ ) with fifteen from Playa del Carmen (prevalence $=23.81 \%$ ), eleven from Akumal (prevalence $=$ $30.56 \%$ ), twelve from Xcalac (prevalence $=9.45 \%$ ), and one from Xahuaxol (prevalence $=7.69 \%$, Table 4 ). These data were also tested by western blot analysis obtaining 84 positive sera from the total, indicating a prevalence of $20.39 \%$, with 45 positive sera from the state of Yucatan (prevalence $=$ $26.01 \%$ ) and 39 from Quintana Roo (prevalence $=16.32 \%$ ). The agreement between the ELISA/Fe-SODe and western blot analysis/Fe-SODe for L. mexicana was $99 \%$.

The use of Fe-SODe as the antigenic fraction is very sensitive for the detection of leishmaniasis, detecting a very small number of false positives [19]. To demonstrate the possible absence of cross-reactivity between the different species of Leishmania, ELISA studies were performed with the FeSODe of L. mexicana, L. infantum, and L. braziliensis as the antigen fraction to analyze the 412 canine sera. Only four sera $(0.97 \%)$ were positive for the three species of Leishmania.

However, 17 sera were positive to both L. mexicana and $L$. braziliensis indicating a prevalence of both species 
TABle 2: The relationship between positive sera of dogs from the Peninsula of Yucatan (Mexico) and Trypanosomatids, by ELISA and Western blot analysis, against different antigen fractions of Leishmania braziliensis.

\begin{tabular}{|c|c|c|c|}
\hline \multicolumn{4}{|c|}{ Leishmania braziliensis } \\
\hline \multirow{2}{*}{ SERA } & \multicolumn{2}{|c|}{ ELISA } & \multirow{2}{*}{$\begin{array}{c}\text { WB } \\
\text { SODe }\end{array}$} \\
\hline & $\mathrm{H}$ & SODe & \\
\hline 1 & + & & \\
\hline 9 & & + & + \\
\hline 10 & & + & + \\
\hline 11 & & + & + \\
\hline 12 & & + & + \\
\hline 31 & & + & + \\
\hline 32 & & + & - \\
\hline 35 & & + & + \\
\hline 37 & & + & + \\
\hline 47 & & + & + \\
\hline 57 & & + & + \\
\hline 64 & & + & + \\
\hline 71 & & + & + \\
\hline 73 & & + & + \\
\hline 74 & & + & - \\
\hline 106 & & + & + \\
\hline 187 & & + & + \\
\hline 207 & & + & + \\
\hline 240 & & + & + \\
\hline 245 & + & + & - \\
\hline 246 & & + & + \\
\hline 260 & + & & \\
\hline 262 & + & & \\
\hline 270 & & + & - \\
\hline 271 & & + & + \\
\hline 272 & + & + & + \\
\hline 313 & & + & + \\
\hline 314 & & + & + \\
\hline 354 & & + & + \\
\hline 362 & + & + & + \\
\hline 363 & + & + & + \\
\hline 364 & & - & + \\
\hline 373 & & + & + \\
\hline TOT & 9 & 29 & 26 \\
\hline
\end{tabular}

*Antigen fraction: Total parasite extract $(\mathrm{H})$ and excreted iron superoxide dismutase by promastigotes from Leishmania braziliensis (Fe-SODe).

simultaneously to be $4.13 \%$. With respect to L. mexicana and $L$. infantum, only 9 sera were positive for both species (prevalence $=2.18 \%$ ). Only eight sera were positive for both $L$. braziliensis and $L$. infantum, indicating a prevalence of $1.94 \%$ (Table 5).

To verify the data, canine sera were also analyzed by western blot analysis using Fe-SODe of the three species of Leishmania as the antigenic fraction. The sensitivity obtained for the ELISA/Fe-SODe over the western blot was $96.2 \%$ for $L$. braziliensis and $100 \%$ for $L$. infantum and $L$. mexicana. The specificity obtained with this technique was 99\% for L. braziliensis, $99.7 \%$ for L. mexicana, and $99.5 \%$ for
L. infantum. The Kappa value was 1 for the three species of Leishmania, as seen in Table 6.

\section{Discussion}

In 1993, three dogs were diagnosed with leishmaniasis, whose owners were also infected in the state of Quintana Roo, Mexico [20]. This relationship between dogs and people infected with leishmaniasis was previously observed in other countries such as Argentina and Brazil [21, 22].

The increase in the canine population, in addition to the social role of dogs in different cultures, makes therelationship 
TABLe 3: The relationship of positive sera of dogs from the Peninsula of Yucatan (Mexico) with Trypanosomatids by ELISA and Western blot analysis against different antigen fractions of Leishmania infantum.

\begin{tabular}{|c|c|c|c|}
\hline \multicolumn{4}{|c|}{ Leishmania infantum } \\
\hline \multirow{2}{*}{ SERA } & \multicolumn{2}{|c|}{ ELISA } & \multirow{2}{*}{$\begin{array}{r}\text { WB } \\
\text { SODe }\end{array}$} \\
\hline & $\mathrm{H}$ & SODe & \\
\hline 10 & & + & + \\
\hline 12 & & + & + \\
\hline 84 & + & + & + \\
\hline 190 & & + & + \\
\hline 207 & & + & + \\
\hline 275 & & + & + \\
\hline 280 & & + & + \\
\hline 283 & & + & + \\
\hline 286 & & + & + \\
\hline 294 & & + & + \\
\hline 295 & & + & - \\
\hline 302 & & + & + \\
\hline 313 & & + & + \\
\hline 314 & & + & + \\
\hline 335 & + & & \\
\hline 358 & & + & + \\
\hline 360 & & + & + \\
\hline 361 & & + & + \\
\hline 362 & & + & + \\
\hline 363 & & + & + \\
\hline 364 & & + & + \\
\hline 365 & & + & + \\
\hline 370 & & + & + \\
\hline 372 & & + & + \\
\hline 373 & & + & + \\
\hline 374 & & + & - \\
\hline TOT & 2 & 25 & 23 \\
\hline
\end{tabular}

* Antigen fraction: Total parasite extract $(\mathrm{H})$ and excreted iron superoxide dismutase by promastigotes from Leishmania infantum (Fe-SODe).

of dogs with humans even closer. The risk of human infection increases with greater relationships between dogs and their wild environment. The risk of human infection also increases with the presence of vectors in the owners homes, which is increasingly common given the successful adaptation of blood-sucking arthropods (mosquitoes, ticks, fleas, flies, etc.) in the domestic environment [23].

Numerous studies support the possibility that dogs are the most important reservoirs for leishmaniasis, cutaneous, mucocutaneous, and visceral, in humans $[20,24,25]$. It is therefore, necessary to control and monitor these animals to prevent them from becoming a problem for human health.

In Mexico, and more specifically in the Yucatan Peninsula, which is an area considered endemic for leishmaniasis, susceptibility of dogs to Leishmania resembles that described in other Latin American countries. However, it appears that the dogs studied in this area seem to be exposed to greater risks of infection than their counterparts in other countries studied [20].

In this study, we found that the dominant species in dogs in the Yucatan Peninsula is L. mexicana, where we found the prevalence to be $20.63 \%$ with the ELISA/Fe-SODe. These data are consistent with those published by other authors $[20,26]$. If we analyze the prevalence values according to the origin of the dogs, we found that the prevalence of $L$. mexicana in dogs from the state of Quintana Roo is $16.32 \%$, while the prevalence in dogs from the state of Yucatan is $26.59 \%$.

In 2005, Andrade and colleagues suspected the presence of $L$. braziliensis in the Yucatan Peninsula. Previous studies in dogs living in wild areas in Tulum and Celestum (Yucatan Peninsula) showed a significant presence of this species with the prevalence at $32.8 \%$ [17]. In another study on canine sera from the Canine and Feline Control Center and from private clinics in Merida (Yucatan State), the prevalence of $L$. braziliensis was found to be $8.2 \%$ [27]. On this occasion, we found the prevalence to be $7.52 \%$ in the Yucatan Peninsula, corresponding to $11.56 \%$ in the state of Yucatan and $4.60 \%$ in Quintana Roo. The presence of L. braziliensis in Mexico and, more specifically, in the Yucatan Peninsula, was only recently discovered. The spread of this species from the displacement of the vector and/or reservoirs from the neighboring countries, Belize and Guatemala, where the disease has been reported $[2,28,29]$ is now very clear. This may explain the prevalence of $4.72 \%$ for L. braziliensis detected in Xcalac, a town located near Belize (Figure 1).

The species causing visceral leishmaniasis in the American continent is L. infantum (syn. chagasi). The role of the vector, Lutzomyialongipalpis, involved in transmission in this area, and the dog's role as a reservoir for this parasite [24], are now understood. Previous studies demonstrated the presence of L. infantum (syn. chagasi) in the city of Merida (Yucatan), with prevalence of $11.9 \%$ [27]. In our study, we obtained a prevalence of $6.07 \%$ in the Yucatan Peninsula. There is a very large variation in the prevalence of $L$. infantum (syn. chagasi) within the two states sampled. In the state of Yucatan we found, a prevalence of only $1.73 \%$, while in the state of Quintana Roo we found, a prevalence of $9.21 \%$. Of note is the prevalence of $L$. infantum of $15.75 \%$ detected in the city of Xcalac (Quintana Roo). This could be due to the proximity between the region in which the city of Xcalac lies and the countries of Belize and Guatemala, where there is a high prevalence of L. infantum [2].

In this study, we found that the prevalence of antibodies to $L$. mexicana in the dog sera tested is much higher than those found against L. braziliensis and L. infantum (syn. chagasi). Specific antibodies of different species of Leishmania have been detected in more than one dog studied. However, this was not due to cross-reaction as the prevalence of multiantibodies is relatively low and the antibodies are very distinct from each other (Table 5). Therefore, cases of co-infections can be considered.

Western blot analysis has a higher sensitivity than ELISA. When comparing the results obtained from the ELISA/FeSODe to those obtained from the western blot analysis, we found very high values of agreement between the 
TABle 4: The relationship of positive sera of dogs from the Peninsula of Yucatan (Mexico) with Trypanosomatids by ELISA and Western blot analysis against different antigen fractions of Leishmania mexicana.

\begin{tabular}{|c|c|c|c|}
\hline \multicolumn{4}{|c|}{ Leishmania mexicana } \\
\hline \multirow{2}{*}{ SERA } & \multicolumn{2}{|c|}{ ELISA } & \multirow{2}{*}{$\begin{array}{c}\text { WB } \\
\text { SODe }\end{array}$} \\
\hline & $\mathrm{H}$ & SODe & \\
\hline 9 & & + & + \\
\hline 11 & & + & + \\
\hline 12 & + & + & + \\
\hline 14 & & + & + \\
\hline 18 & & + & + \\
\hline 21 & & + & + \\
\hline 29 & & + & + \\
\hline 30 & & + & + \\
\hline 32 & & + & + \\
\hline 33 & & + & + \\
\hline 35 & & + & + \\
\hline 36 & & + & + \\
\hline 37 & & + & + \\
\hline 39 & + & & \\
\hline 41 & & + & + \\
\hline 42 & & + & + \\
\hline 44 & & + & + \\
\hline 45 & & + & + \\
\hline 46 & & + & + \\
\hline 47 & & + & + \\
\hline 48 & & + & + \\
\hline 50 & & + & + \\
\hline 57 & & + & + \\
\hline 60 & & + & + \\
\hline 61 & + & & \\
\hline 71 & & + & + \\
\hline 72 & & + & + \\
\hline 73 & & + & + \\
\hline 83 & + & + & + \\
\hline 84 & + & + & + \\
\hline 85 & & + & + \\
\hline 86 & & + & + \\
\hline 93 & & + & + \\
\hline 97 & + & & \\
\hline 98 & & + & + \\
\hline 102 & & + & + \\
\hline 104 & & + & + \\
\hline 106 & & + & + \\
\hline 108 & & + & + \\
\hline 109 & & + & + \\
\hline 110 & & + & + \\
\hline 115 & & + & - \\
\hline 123 & & + & + \\
\hline 125 & & + & + \\
\hline 130 & & + & + \\
\hline 133 & & + & + \\
\hline 134 & & + & + \\
\hline
\end{tabular}


Table 4: Continued.

\begin{tabular}{|c|c|c|c|}
\hline \multicolumn{4}{|c|}{ Leishmania mexicana } \\
\hline 137 & & + & + \\
\hline 142 & + & & \\
\hline 148 & + & & \\
\hline 151 & & + & + \\
\hline 156 & & + & + \\
\hline 162 & & + & + \\
\hline 165 & & + & + \\
\hline 166 & & + & + \\
\hline 167 & & + & + \\
\hline 170 & & + & + \\
\hline 174 & & + & + \\
\hline 189 & & + & + \\
\hline 191 & & + & + \\
\hline 192 & & + & + \\
\hline 193 & & + & + \\
\hline 202 & & + & + \\
\hline 204 & & + & + \\
\hline 207 & + & + & + \\
\hline 220 & & + & + \\
\hline 221 & & + & + \\
\hline 223 & & + & + \\
\hline 224 & & + & + \\
\hline 225 & & + & + \\
\hline 231 & & + & + \\
\hline 232 & + & & \\
\hline 236 & + & & \\
\hline 238 & + & + & + \\
\hline 239 & & + & + \\
\hline 240 & & + & + \\
\hline 245 & & + & + \\
\hline 246 & & + & + \\
\hline 260 & + & & \\
\hline 263 & & + & + \\
\hline 277 & & + & + \\
\hline 283 & & + & + \\
\hline 286 & & + & + \\
\hline 295 & & + & + \\
\hline 302 & & + & + \\
\hline 313 & & + & + \\
\hline 314 & & + & + \\
\hline 320 & & + & + \\
\hline 325 & & + & + \\
\hline 336 & + & + & + \\
\hline 337 & & + & + \\
\hline 344 & + & & \\
\hline 393 & & + & + \\
\hline 406 & + & + & + \\
\hline TOT & 16 & 85 & 84 \\
\hline
\end{tabular}


TABle 5: Detection of co-infection in 412 sera of dogs of the Yucatan Peninsula (Mexico) by ELISA.

\begin{tabular}{lcc}
\hline Trypanosomatids $^{\mathrm{a}}$ & No of sera positive & Prevalence \\
\hline L.mex/L.bra & 17 & $4.13 \%$ \\
L.mex/L.inf & 9 & $2.18 \%$ \\
L.bra/L.inf & 8 & $1.94 \%$ \\
L.mex/L.bra/L.inf & 4 & $0.97 \%$ \\
\hline
\end{tabular}

${ }^{a}$ Promastigote forms of L. mexicana (L.mex), L. braziliensis (L.bra) and $L$. infantum (L inf).

TABLE 6: Result of the indices that evaluate the reliability of the diagnostic test (ELISA) using the Fe-SODe fraction of the different strains of Leishmania in sera of dogs of the Yucatan Peninsula (Mexico).

\begin{tabular}{lccc}
\hline & L. braziliensis & L. infantum & L. mexicana \\
\hline Sensitivity & $96.20 \%$ & $100.00 \%$ & $100.00 \%$ \\
Specificity & $99.00 \%$ & $99.70 \%$ & $99.50 \%$ \\
Positive predictive value & $86.20 \%$ & $98.80 \%$ & $92.00 \%$ \\
Negative predictive value & $99.70 \%$ & $100.00 \%$ & $100.00 \%$ \\
Kappa value & 1 & 1 & 1 \\
\hline
\end{tabular}

two techniques, being $99 \%$ for $L$. mexicana, $84 \%$ for $L$. braziliensis, and $92 \%$ for L. infantum.

However, due to its low cost and easy reproducibility, very important considerations in low socioeconomic countries in which leishmaniasis is endemic, ELISA/Fe-SODe may be viewed as the more ideal technique. It has specificity between 99\% and 99.7\%, sensitivity between $96.2 \%$ and $100 \%$, a positive predictive value between $86.2 \%$ and $98.8 \%$, a negative predictive value between $99.7 \%$ and $100 \%$ and a Kappa index of 1 (Table 6).

In summary, this study demonstrates the presence of at least three species of Leishmania (L. mexicana, L. braziliensis, and L. infantum) in the canine populations of the towns of Playa del Carmen, Akumal, Xcalac, Xahuaxol (Quintana Roo State), Molas, and Xmatkuil (Yucatan State). Dogs can therefore be regarded as an important source of transmission of leishmaniasis. A thorough epidemiological study of this population, both wild and urban, to design an effective control plan against this disease is, therefore, required. Such a study could be extended to other Mexican states such as Campeche and other neighboring countries. Because of the close relationship between dogs and their owners, a similar study should be done with the human population in these regions. Finally, these results provide further confirmation that Fe-SODe is a good antigen fraction for serodiagnosis in epidemiological studies.

\section{Acknowledgment}

The authors would like to express our thanks to E. Guerrero López in culture media preparation and in vitro culture.

\section{References}

[1] U. Sharma and S. Singh, "Insect vectors of Leishmania: distribution, physiology and their control," Journal of Vector Borne Diseases, vol. 45, no. 4, pp. 255-272, 2008.

[2] World Health Organization, "Control of the Leishmaniases," World Health Organization Technical Report Series, no. 949, pp. 1-186, 2010.

[3] J. Alvar, C. Cañavate, R. Molina, J. Moreno, and J. Nieto, "Canine Leishmaniasis," Advances in Parasitology, vol. 57, pp. 1-88, 2004.

[4] W. Mayrink, P. Williams, M. V. Coelho et al., "Epidemiology of dermal Leishmaniasis in the Rio Doce Valley, State of Minas Gerais, Brazil," Annals of Tropical Medicine and Parasitology, vol. 73, no. 2, pp. 123-137, 1979.

[5] J. E. Tolezano, S. R. B. Uliana, H. H. Taniguchi et al., "The first records of Leishmania (Leishmania) amazonensis in dogs (Canis familiaris) diagnosed clinically as having canine visceral Leishmaniasis from Araçatuba County, São Paulo State, Brazil," Veterinary Parasitology, vol. 149, no. 3-4, pp. 280-284, 2007.

[6] F. Dantas-Torres, "Canine leishmaniosis in South America," Parasites and Vectors, vol. 2, no. 1, supplement, article S1, 2009.

[7] R. Reithinger and C. R. Davies, "Is the domestic dog (Canis familiaris) a reservoir host of American cutaneous Leishmaniasis? A critical review of the current evidence," American Journal of Tropical Medicine and Hygiene, vol. 61, no. 4, pp. 530-541, 1999.

[8] V. M. C. L. Cortada, M. E. C. Doval, M. A. A. Souza Lima et al., "Canine visceral leishmaniosis in Anastácio, Mato Grosso do Sul State, Brazil," Veterinary Research Communications, vol. 28, no. 5, pp. 365-374, 2004.

[9] P. V. S. Queiroz, G. R. G. Monteiro, V. P. S. Macedo et al., "Canine visceral Leishmaniasis in urban and rural areas of Northeast Brazil," Research in Veterinary Science, vol. 86, no. 2, pp. 267-273, 2009.

[10] A. P. da Costa-Val, R. R. Cavalcanti, N. de Figueiredo Gontijo et al., "Canine visceral Leishmaniasis: relationships between clinical status, humoral immune response, haematology and Lutzomyia (Lutzomyia) longipalpis infectivity," Veterinary Journal, vol. 174, no. 3, pp. 636-643, 2007.

[11] C. B. Palatnik-De-Sousa, W. R. Dos Santos, J. C. França-Silva et al., "Impact of canine control on the epidemiology of canine and human visceral Leishmaniasis in Brazil," American Journal of Tropical Medicine and Hygiene, vol. 65, no. 5, pp. 510-517, 2001.

[12] T. M. Mohapatra, D. P. Singh, M. R. Sen, K. Bharti, and S. Sundar, "Comparative evaluation of rK9, rK26 and rK39 antigens in the serodiagnosis of Indian visceral Leishmaniasis," Journal of Infection in Developing Countries, vol. 4, no. 2, pp. 114-117, 2010.

[13] M. Rasouli, A. Z. Hoseini, B. Kazemi, A. Alborzi, and S. Kiany, "Expression of recombinant heat-shock protein 70 of MCAN/IR/96/LON-49, a tool for diagnosis and future vaccine research," Iranian Journal of Immunology, vol. 6, no. 2, pp. 7586, 2009.

[14] M. N. Saridomichelakis, "Advances in the pathogenesis of canine leishmaniosis: epidemiologic and diagnostic implications," Veterinary Dermatology, vol. 20, no. 5-6, pp. 471-489, 2009.

[15] C. Marín, S. S. Longoni, H. Mateo et al., "The use of an excreted superoxide dismutase in an ELISA and Western blotting for the diagnosis of Leishmania (Leishmania) infantum 
naturally infected dogs," Parasitology Research, vol. 101, no. 3, pp. 801-808, 2007.

[16] C. Marín, S. S. Longoni, J. Urbano et al., "Enzyme-linked immunosorbent assay for superoxide dismutase-excreted antigen in diagnosis of sylvatic and andean cutaneous Leishmaniasis of Peru," American Journal of Tropical Medicine and Hygiene, vol. 80, no. 1, pp. 55-60, 2009.

[17] S. S. Longoni, C. Marín, C. H. Sauri-Arceo et al., "An ironsuperoxide dismutase antigen-based serological screening of dogs indicates their potential role in the transmission of cutaneous Leishmaniasis and trypanosomiasis in Yucatan, Mexico," Vector-Borne and Zoonotic Diseases, vol. 11, no. 7, pp. 815-821, 2011.

[18] C. Marín, A. B. Hitos, I. Rodríguez-González, M. Dollet, and M. Sánchez-Moreno, "Phytomonas iron superoxide dismutase: a possible molecular marker," FEMS Microbiology Letters, vol. 234, no. 1, pp. 69-74, 2004.

[19] C. Marín and M. Sánchez-Moreno, "The trypanosomiasis diagnosis: a review on the role of the superoxide dismutase as molecular marker," Current Review in Microbiology, vol. 1, pp. $1-12,2009$.

[20] O. Velasco Castrejón, B. Rivas Sánchez, A. Mungía Saldaña, and O. Hobart, "Leishmaniasis cutánea de perros en México," Enfermedades Infecciosas y Microbiología, vol. 29, pp. 135-140, 2009.

[21] N. J. Taranto, R. Marinconz, C. E. Caffaro, S. P. Cajal, and E. L. Malchiodi, "Mucocutaneous lesion due to American tegumentary leismaniosis in naturally infected dogs in Salta, Argentina," Revista Argentina de Microbiologia, vol. 32, no. 3, pp. 129-135, 2000.

[22] J. D. Marco, P. A. Barroso, M. Calvopiña et al., "Species assignation of Leishmania from human and canine American tegumentary Leishmaniasis cases by multilocus enzyme electrophoresis in north Argentina," American Journal of Tropical Medicine and Hygiene, vol. 72, no. 5, pp. 606-611, 2005.

[23] D. Otranto, F. Dantas-Torres, and E. B. Breitschwerdt, "Managing canine vector-borne diseases of zoonotic concern: part one," Trends in Parasitology, vol. 25, no. 4, pp. 157-163, 2009.

[24] F. Dantas-Torres, "The role of dogs as reservoirs of Leishmania parasites, with emphasis on Leishmania (Leishmania) infantum and Leishmania (Viannia) braziliensis," Veterinary Parasitology, vol. 149, no. 3-4, pp. 139-146, 2007.

[25] E. A. Castro, V. Thomaz-Soccol, C. Augur, and E. Luz, "Leishmania (Viannia) braziliensis: epidemiology of canine cutaneous Leishmaniasis in the State of Paraná (Brazil)," Experimental Parasitology, vol. 117, no. 1, pp. 13-21, 2007.

[26] L. O. Andrade and N. W. Andrews, "Opinion: the Trypanosoma cruzi-host-cell interplay: location, invasion, retention," Nature Reviews Microbiology, vol. 3, no. 10, pp. 819-823, 2005.

[27] G. Arjona-Jiménez, N. Villegas, A. López-Céspedes, C. Marín, S. S. Longoni, and Bolio-González, "Prevalence of antibodies against three species of Leishmania (L. mexicana, L. braziliensis, L. infantum) and possible associated factors in dogs from Mérida, Yucatán, Mexico using SOD-ELISA and Western blot," Transactions of the Royal Society of Tropical Medicine and Hygiene, vol. 106, pp. 252-258, 2012.

[28] J. Soto, B. A. Arana, J. Tolado et al., "Miltefosine for new world cutaneous Leishmaniasis," Clinical Infectious Diseases, vol. 38, no. 9, pp. 1266-1272, 2004.

[29] J. Schnedl, H. Auer, M. Fischer, H. Tomaso, T. Pustelnik, and G. Mooseder, "Cutaneous Leishmaniasis—an import from Belize," Wiener Klinische Wochenschrift, vol. 119, no. 3, pp. 102-105, 2007. 

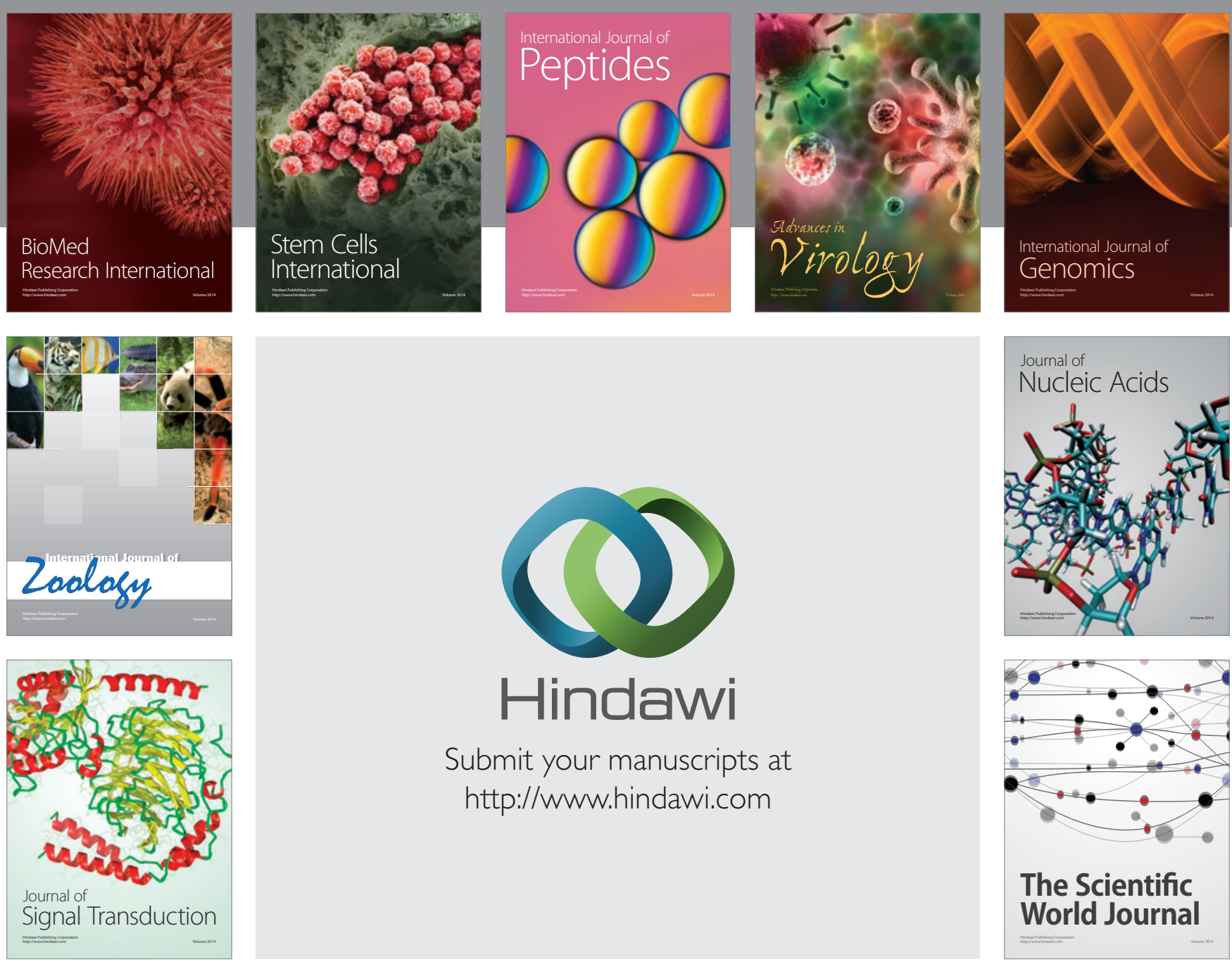

Submit your manuscripts at

http://www.hindawi.com
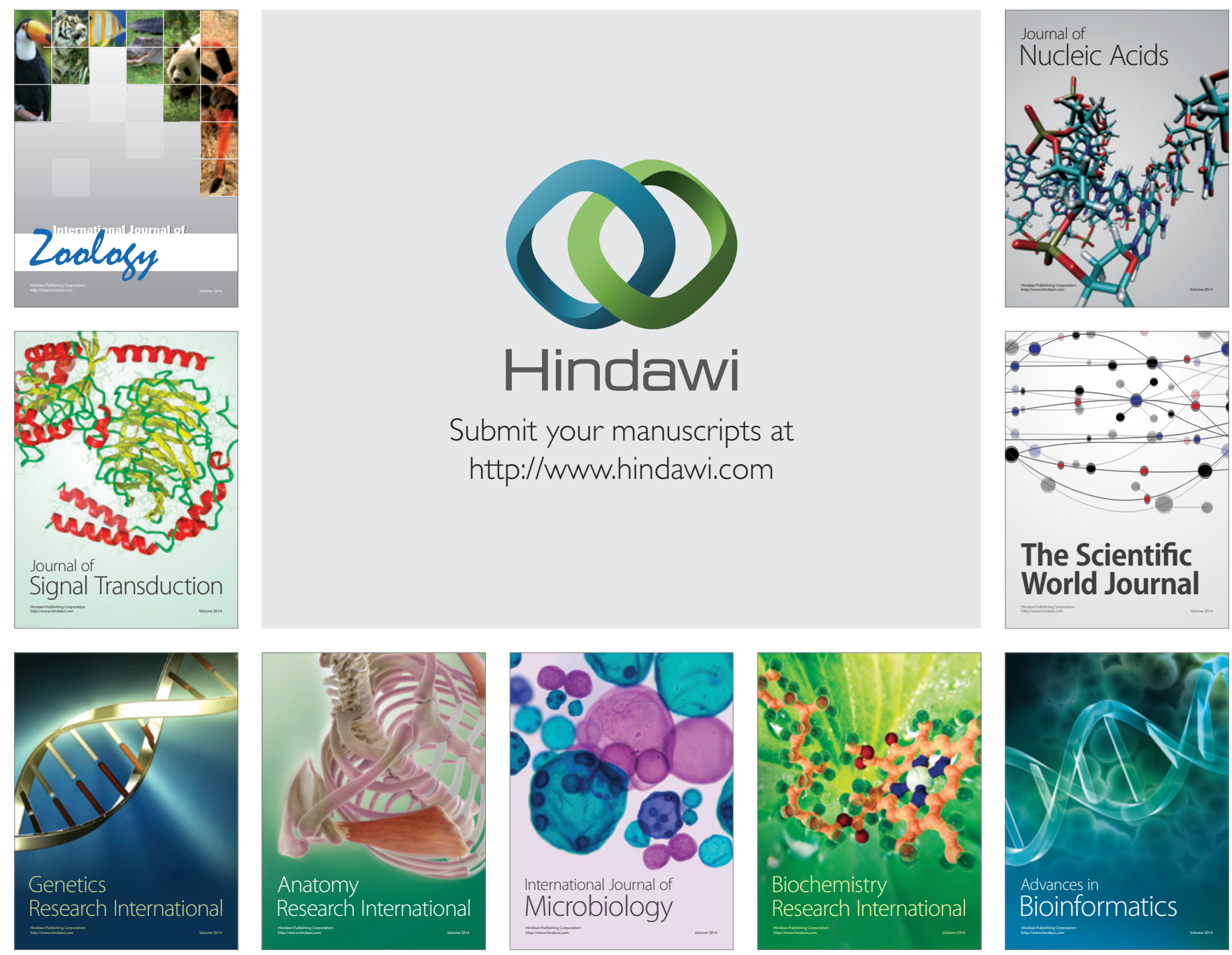

The Scientific World Journal
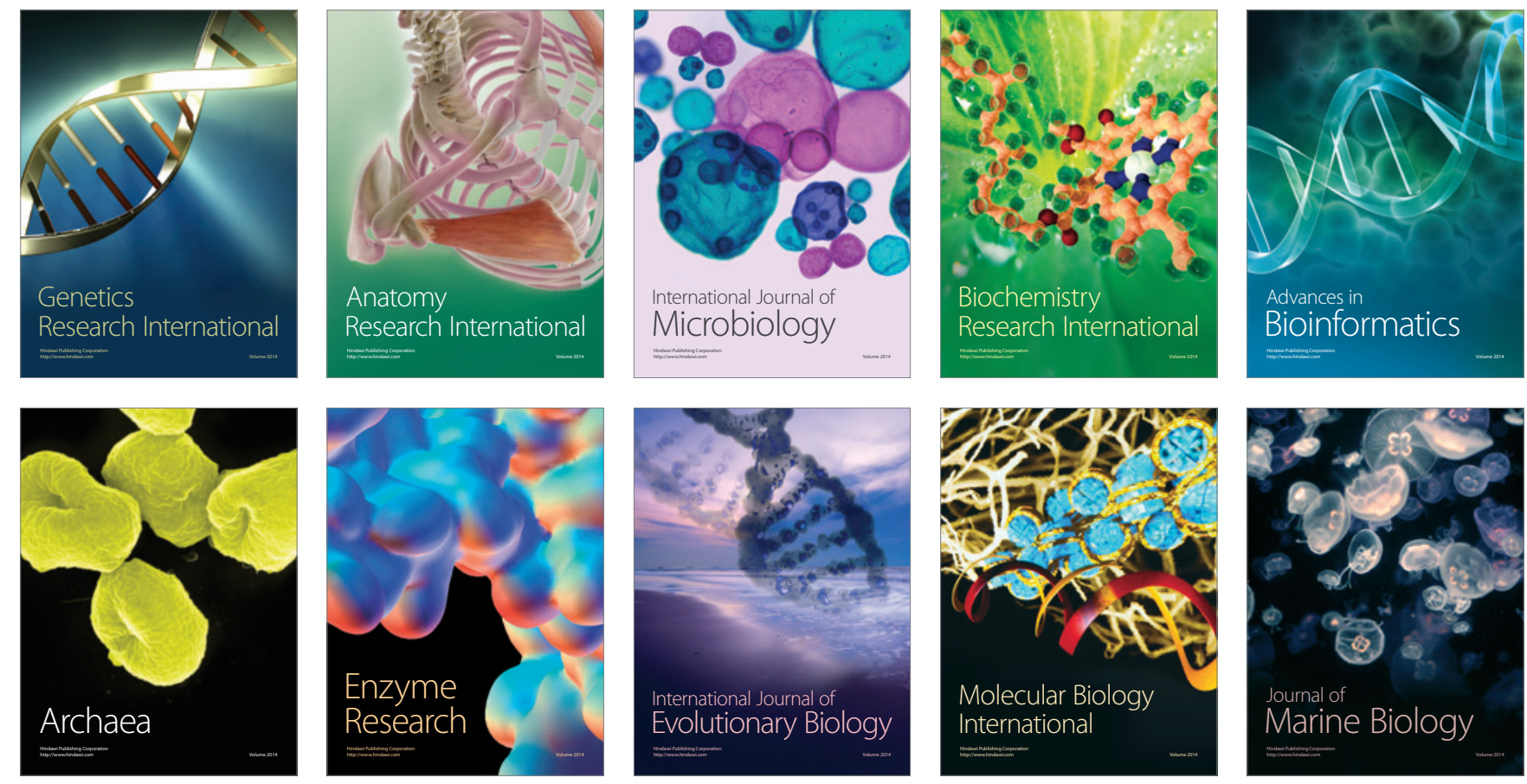